\title{
A DISPUTA PELO LEGADO EM MEGAEVENTOS ESPORIIVOS NO BRASIL
}

\author{
Martin Curi \\ Museu Nacional/Universidade Federal do Rio de Janeiro - Brasil
}

Resumo: Desde que o Brasil foi escolhido sede da Copa do Mundo de Futebol de 2014 e dos Jogos Olímpicos de 2016 o tema megaeventos esportivos é um dos principais temas em pauta no Brasil. Por causa dessas competições há um investimento pesado em várias áreas como transporte, infraestrutura e principalmente a construção de vários novos estádios no país inteiro. Essas obras são parte de um projeto maior que obedece a normas internacionais e interfere gravemente na vida dos cidadãos brasileiros. Por isso, há uma grande discussão sobre usos e abusos, significado internacional e tendências globais de megaeventos esportivos. Em geral, a discussão gira em torno daquilo que é chamado de "legado". O presente artigo propõe analisar com a ajuda dos conceitos "torneio de valor" e os "panoramas dos fluxos globalizados" de Appadurai a disputa por esse legado.

Palavras-chave: disputa, globalização, legado, megaevento esportivo.

\begin{abstract}
The issue sports mega-events is one of the most important in in Brazil since the country was elected to host the football world cup 2014 and the Summer Olimpics 2016. There is a heavy investment in several areas like transport, infrastructure and especially a number of new stadiums because of these tournaments. These constructions are part of a nationwide project which obeys international norms and interferes seriously in the daily life of the Brazilian citizens. That's the reason why there is happening a strong discussion about the utility, abuses, international meaning and global tendencies of sports mega-events. Normally this discussion is about that what is called "legacy". The present article proposes to analyze with the help of the concepts "tournament of value" and the "scapes of global fluxes" by Appadurai the dispute for this legacy.
\end{abstract}

Keywords: dispute, globalization, legacy, sports mega-events. 
Desde que o Brasil foi escolhido sede da Copa do Mundo de Futebol de 2014 no dia 30 de outubro de 2007, o tema megaeventos esportivos é um dos principais, talvez o principal tema em pauta no Brasil. ${ }^{1}$ Dois anos depois, o Rio de Janeiro foi escolhido sede dos Jogos Olímpicos de Verão de 2016. Essas decisões se tornaram possíveis porque o Rio de Janeiro já sediou em 2007 os Jogos Pan-Americanos, evento que aparentemente foi avaliado pelas federações internacionais de esporte como sucesso. Por causa dessas competições há um investimento pesado em várias áreas como transporte, infraestrutura e principalmente vários novos estádios no país inteiro.

Essas obras são parte de um projeto maior que obedece a normas internacionais e interfere gravemente na vida dos cidadãos brasileiros. Por isso, há uma grande discussão sobre usos e abusos, significado internacional e tendências globais de megaeventos esportivos. Em geral, a discussão gira em torno daquilo que é chamado de "legado".

Os organizadores desses eventos, como representantes das federações esportivas ou membros dos governos, tendem a ficar bastante eufóricos com a situação. Eles apresentam os megaeventos como automaticamente benéficos para o país e sua população. Os megaeventos esportivos são entendidos como um meio de desenvolvimento acelerado do país anfitrião. Essa visão do legado positivo automático está sendo questionada nas ciências sociais há um bom tempo.

Essas posições levam, na discussão pública no Brasil, a dois lados: os defensores e os opositores dos megaeventos. Um lado entende esses eventos como absolutamente positivos e o outro, como nocivos, e por isso sua realização é rejeitada.

Tanto a posição contrária quanto a favorável aos megaeventos são posições políticas e têm, como tal, a sua justificativa. Mas, em alguns eventos, com participação de cientistas sociais no Rio de Janeiro, também tem sido possível perceber que essas posturas estão sendo assumidas também por parcela de acadêmicos dessa referida área de conhecimento. No dia, 26 de abril de 2010, por exemplo, foi realizado um debate intitulado "Intervenções esportivas no tecido urbano" na Universidade Federal do Rio de Janeiro. Nessa ocasião um representante do secretário especial da Copa de 2014 e Olimpíadas de

1 Este artigo resume dados e resultados da minha tese de doutorado (Curi, 2012) que foi elaborado com a ajuda de uma bolsa do CNPq.

Horizontes Antropológicos, Porto Alegre, ano 19, n. 40, p. 65-88, jul./dez. 2013 
2016 do município do Rio de Janeiro, Ruy Cezar, cumpriu seu papel político e defendeu o legado positivo desses eventos. Nas mesas seguintes, alguns cientistas sociais assumiram a posição de que os megaeventos esportivos não trazem quaisquer vantagens para a população e por isso não devem acontecer em solo brasileiro.

Interessante é que, muitas vezes, tanto defensores quanto opositores argumentam apresentando números concretos de ganhos e perdas financeiras, sendo que o saldo final é positivo ou negativo dependendo da linha de argumentação. Fica visível que números sugerem uma credibilidade e objetividade que não têm. $\mathrm{O}$ legado de um megaevento esportivo é algo tão complexo que dificilmente pode ser resumido em poucas palavras ou números. Entretanto, essa complexidade não deve desanimar as ciências sociais, mas, ao contrário, faz dos megaeventos esportivos um desafio, que deve ser objeto de análise. A proposta deste artigo é desenvolver um instrumental teórico antropológico que leve em consideração essa complexidade dos legados e possibilite um caminho de análise que vá além da visão política de apoio ou recusa. Cabe ressaltar que os megaeventos esportivos são ocasiões de extrema importância e interesse para a antropologia, independentemente de posições políticas.

Tem sido comum que o conceito de sociedade do espetáculo de Debord (1992) tenha servido de ponto de partida teórico das ciências sociais, nos seus esforços de analisar megaeventos. Segundo a perspectiva de Debord, os megaeventos esportivos seriam compreendidos certamente como uma expressão máxima da sociedade do espetáculo que se tornou necessária devido à alta saturação dos produtos materiais do mercado mundial. Como o sistema capitalista segue a lógica da contínua produção e geração de lucros, torna-se necessária a criação de espetáculos para dar continuidade à geração de produtos e lucros. Enquanto a vida anterior à sociedade dos espetáculos era vivida diretamente, na visão de Debord (1992) a sociedade do espetáculo é vivida em representações. Viver diretamente significa, nesse caso, seguir o ciclo da natureza. Certas invenções tecnológicas, como, por exemplo, estufas para criar alimentos em qualquer temporada, possibilitaram a negligência do ritmo da natureza. Com esse processo, começou a ser possível produzir mais do que o necessário, e esses produtos necessitam de arenas para serem comercializados: os espetáculos.

É possível tecer duas críticas centrais à argumentação de Debord (1992). A primeira diz respeito à questão do "viver diretamente": o consumo de um 
espetáculo pode ser vivido tão diretamente quanto o consumo de uma maçã na estação natural. A segunda crítica refere-se à suposta alienação dos seres humanos devido às inovações tecnológicas. Estas fazem parte da vida humana e podem ser perfeitamente vividas diretamente. Desde que os povos nômades se tornaram sedentários dificilmente se compreende a nova vida deles como representação e a antiga como vivida diretamente com os ciclos da natureza.

Além do mais, se os consumidores dos espetáculos são alienados, o que dizer de seus produtores? Eles não seriam também alienados? Debord (1992) esboça uma reformulação da teoria marxista da sociedade de classes: produtores e consumidores do espetáculo. Mas se nós vivemos na sociedade do espetáculo, onde tudo é vivido através de representações, então os produtores dos espetáculos também são alienados e a partir daí não há mais classes.

Apesar dessas questões, torna-se bastante válido o raciocínio da utilidade econômica de um espetáculo como um megaevento esportivo. Um megaevento cria produtos, como ingressos, suvenires, notícias ou imagens, que não são imediatamente necessários para a sobrevivência, mas podem ser comercializados. Entretanto, esses eventos vão além da utilidade econômica: são um lugar de troca de informações, de afirmação de status e identidade, ou seja, há também uma utilidade simbólica. Eles podem ser pensados como "torneios de valor":

Torneios de valor são complexos eventos periódicos que, de alguma forma culturalmente definida, se afastam das rotinas da vida econômica. A participação nestes eventos tende a ser simultaneamente um privilégio daqueles que estão no poder e um instrumento de disputa de status entre eles. A moeda corrente destes torneios também tende a ser distinguida por meio de diacríticos culturais muito bem compreendidos. Finalmente, o que está em pauta nestes torneios não é apenas o status, a posição, a fama ou a reputação dos atores, mas a disposição dos principais emblemas de valor da sociedade em questão. Enfim, embora tais torneios de valor ocorram em épocas e lugares especiais, suas formas e resultados sempre trazem conseqüências para as mais mundanas realidades de poder e valor na vida comum. (Appadurai, 2008, p. 36-37).

Tanto os Jogos Pan-Americanos de 2007, a Copa do Mundo de 2014, quanto os Jogos Olímpicos de 2016 são eventos periódicos fora da rotina da vida econômica. Políticos, dirigentes esportivos e outros interessados se mostraram bastante empenhados em enfatizar a sua participação no evento. Além de questões econômicas e urbanísticas estão em disputa também a definição 
de categorias como modernidade, progresso, democracia, mas também corrupção. Ainda não conhecemos os resultados dessa disputa, que serão parte do legado do evento em nível local.

Appadurai (2008) se inspira na sua noção de torneios de valor em rituais que foram descritos na literatura clássica da antropologia, como o potlatch (Boas; Nunt, 1921; Mauss, 1988) e o kula (Malinowski, 1978). Para compreender os megaeventos esportivos como torneios de valor, vale a pena refletir sobre os elementos ritualísticos desses eventos. Essa reflexão em relação ao esporte em geral e o futebol especificamente já foi feita várias vezes. Mas cabe ressaltar que o caráter ritualístico dos megaeventos esportivos é nítido.

Temos, por exemplo, Archetti (2003) e sua concepção das zonas livres, analisada criticamente no que diz respeito à sua validade em relação a jogos comuns de futebol (Curi, 2012). Entretanto as "zonas livres" são uma concepção que tem muita validade para analisarmos os megaeventos esportivos. Vejamos:

Las tendencias ordenadoras de la sociedad están relacionadas con instituciones públicas como la escuela, el servicio militar, el trabajo, las ceremonias públicas y los rituales de nacionalidad. Las zonas "libres", como las propiedades anti-estructurales de la liminaridad y lo sacramental híbrido en el trabajo de Turner [...], permiten la articulación de lenguajes y prácticas que pueden desafiar un dominio público oficial y puritano. Las zonas "libres" son espacios para la mezcla, la aparición de híbridos, la sexualidad y la exaltación de desempeños físicos. En las sociedades modernas, el deporte, los juegos y el baile son sitios privilegiados para el análisis de la libertad y la creatividad cultural. El tango y el fútbol pueden, de esta manera, ser conceptualizados como una amenaza a las ideologías oficiales. (Archetti, 2003, p. 42).

$\mathrm{O}$ autor considera o esporte uma zona limítrofe e de desafio às normas estabelecidas da sociedade. Entretanto, Archetti (2003) se baseia na concepção de liminaridade de Turner (2005), desenvolvida em relação aos ritos de passagem. Turner (2005) diferencia, como muitos antropólogos sociais britânicos, estrutura social e cultura. Para o autor, estrutura social é o sistema formal de relações entre pessoas dentro de uma dada sociedade. A posição de cada pessoa é denominada status. Já cultura seriam as representações que cada sistema social encontra para expressar aquele status. Os ritos de passagem são, portanto, as expressões culturais para demonstrar a mudança de status 
de um indivíduo. Esses ritos têm uma fase de separação do status antigo, uma fase de margem e uma fase de agregação ao novo status.

"Se o nosso modelo básico de sociedade é o de uma 'estrutura de posições', devemos encarar o período de margem ou 'liminaridade' como uma situação interestrutural" (Turner, 2005, p. 137). Isso significa que as pessoas que estão na situação da liminaridade se tornaram "[...] seres transicionais [que têm a característica] de não terem nada. Não têm status, propriedade, insígnia, vestimenta secular, graduação, posição de parentesco, nada que possa distingui-los, estruturalmente, de seus companheiros" (Turner, 2005, p. 137). Em outro momento, Turner afirma que tais seres seriam invisíveis porque estão fora do grupo social. Ou seja, quando Archetti (2003) se refere às propriedades antiestruturais do futebol e do tango, ele quer dizer que os participantes desses ritos estariam temporariamente sem status - e, portanto, fora da sociedade -, sendo que a partir dessa posição poderiam desafiar as regras da sociedade.

Seguindo esse raciocínio, esporte e arte seriam zonas livres que estariam fora da sociedade, sendo que zonas, digamos, sérias como, por exemplo, a economia, a política e a justiça estariam dentro da sociedade. Essas zonas livres seriam o espaço para a criatividade, a produção de híbridos e, portanto, uma ameaça para as ideologias oficiais. Desse ponto de vista, o esporte teria o poder de mudar a sociedade.

Entretanto, será que o campo esportivo é de fato um espaço privilegiado, distinto de outros da sociedade, onde temos mais liberdade? Os nossos informantes nas pesquisas podem declarar que se sentem mais livres e que podem esquecer o dia a dia, o trabalho e as preocupações quando estão num jogo. Porém, isso não significa que o esporte estaria fora da sociedade, mas, ao contrário, muito bem integrado.

Vejamos o exemplo do futebol no Brasil. Para começar, o futebol não ocorre numa invisibilidade, sobretudo o futebol profissional, que é visto por uma multidão que ocupa os estádios e por uma multidão ainda maior que assiste às partidas pela televisão. Esses espectadores, após as partidas, costumam fazer comentários. Aliás, é impressionante como o futebol é um tema onipresente. Pessoas que não se conhecem conversam sobre futebol da mesma maneira como se fala em outros países sobre o clima.

Central para o conceito de liminaridade de Turner (2005) é a ideia de que os seres liminares não têm nada, sobretudo status, porque saem de um status 
para entrar em outro. O status e as posições dos envolvidos em um jogo de futebol profissional são muito bem definidos, inclusive representados através de uniformes e adornos: temos os dois times com seus uniformes, a faixa de capitão, o uniforme do goleiro, a posição destacada dos árbitros, os uniformes da polícia e de outros agentes de segurança, funcionários dos clubes, os crachás de pessoas envolvidos na organização, etc.

É muito sedutor considerar o futebol como um espaço extremamente democrático, porque supostamente todos os espectadores seriam iguais num estádio, sem distinção de status (ver, por exemplo, DaMatta, 1982). Entretanto temos de insistir em discordar dessa hipótese. O espaço dos torcedores é hierarquicamente dividido em setores mais caros, mais baratos e setores para os quais apenas convidados têm acesso. Os torcedores sabem muito bem onde estão os poderosos e que o lugar deles é inalcançável. Ao que parece, os jogos de futebol são ritos que reforçam a hierarquia existente ao invés de desafiá-la.

Isso vale para jogos comuns dos campeonatos nacionais e regionais. Uma derrota ou uma vitória num Fla-Flu não altera de fato em longo prazo o status dos clubes, jogadores e torcidas envolvidos. Mas há jogos especiais, que podem sim modificar o status, entre os quais podemos citar as finais de Copa do Mundo, Jogos Olímpicos ou Copa Libertadores. Normalmente este valor do jogo depende também do contexto. Para a seleção brasileira é absolutamente normal, e até uma obrigação, jogar uma primeira fase de uma Copa do Mundo e avançar para as oitavas de final. Ao contrário disso, só houve uma única vez na história de Copas do Mundo uma participação de uma seleção angolana. Portanto, os 23 jogadores angolanos dessa equipe certamente mudaram seu status no seu país, simplesmente porque fizeram parte dessa seleção.

Esse é também o motivo por que a convocação de jogadores para uma seleção é feita de forma bem ritualizada. Os nomes dos convocados são mantidos em sigilo até o momento do ritual, ou seja, eles ficam invisíveis, exatamente como descrito por Turner (2005). A escalação para a equipe do seu clube é normal e por isso não precisa do reforço de um ritual. Ao contrário disso, a convocação para a seleção deve ganhar mais valor e levantar o status do jogador. Por isso, há o ritual da convocação. O ritual é um instrumento de mudança de status.

Podemos lembrar um clipe produzido em Portugal, no qual o então técnico da seleção portuguesa, Luiz Felipe Scolari, convoca não os jogadores, mas todos os portugueses para a Euro de 2004, realizada no próprio país. Os 
produtores do clipe estavam conscientes da força do ritual de uma convocação, mas queriam ampliar isso para todo o país. Por que fizeram isso?

Acredito que esse fato tem a ver com o significado de sediar um megaevento esportivo. Esse torneio de valor não só valoriza os atletas participantes, mas muito mais pessoas e inclusive muda o status da localidade-sede - seja cidade, seja país. Novamente podemos observar os rituais, principalmente, no processo da escolha das sedes. Todos os candidatos têm de preencher um questionário de candidatura padronizado, que deve criar condições igualitárias. Com base nesse questionário um colégio eleitoral vota em sessões fechadas ao público para eleger o escolhido.

$\mathrm{O}$ anúncio acontece numa forma bem ritualizada. O nome do vencedor consta num envelope, ou seja, está sigiloso e escondido até o momento do anúncio, quando o envelope é aberto. Esse ritual precisa ser mantido mesmo quando há apenas um único candidato e, portanto, não existe dúvida sobre o eleito, como foi o caso da escolha do Brasil como sede da Copa do Mundo de 2014. Fica nítido que o ritual deve enfatizar algumas mensagens, como, por exemplo, que a sede escolhida acaba de ter seu status mudado.

Mesmo assim gostaria de manter o ceticismo frente às grandes transformações automáticas. Estas somente tornam-se possíveis caso haja alterações baseadas no arranjo das categorias da cultura existente. Essas transformações são muitas vezes incentivadas por eventos como descobertas, invenções ou mudanças naturais. Megaeventos esportivos podem ser um desses eventos. O seu poder reside na posição destacada na hierarquia dos seus idealizadores. Mesmo assim, uma dada cultura exerce tanta força que mesmo esses megaeventos esportivos tendem a ser incluídos na cultura local e adaptados. Ou seja, é muito mais o novo signo que está sendo transformado do que a cultura local.

É válido explicar a questão da mudança social com o auxílio de Sahlins (2007), que entende a cultura como um arranjo de categorias socialmente construído e que está numa contínua transformação estrutural. Trata-se de um processo simbólico. Aquele arranjo é a cultura-tal-como-constituída, mas Sahlins chama a atenção para a existência de uma cultura-tal-como-vivida, que é a interpretação e realização que cada indivíduo faz da cultura-tal-como-constituída. Esse projeto individual é dominado pelo pragmatismo e racionalidade do indivíduo que influencia e pode até mudar a cultura-tal-como-constituída, dependendo de algumas condições: 
[...] das improvisações que podem ser logicamente motivadas por analogia, metáfora ou coisas similares; da liberdade institucional de fazê-lo; da posição do autor numa hierarquia social que confere peso estrutural a sua ação, faz que esta tenha maior ou menor consequência para os outros. (Sahlins, 2007, p. 312, grifo meu).

A partir daí Sahlins (2007, p. 313, grifo meu) analisou dois mecanismos de interação entre estrutura e ação individual: “[...] o deslocamento funcional das relações entre signos na ação pessoal e a reavaliação prática dos signos no famoso 'contexto da situação'."

Uma parte importante deste contexto da situação de megaeventos esportivos do século XXI é que eles não são mais apenas de interesse local ou nacional, mas são torneios de valor globalizados. Tanto o local anfitrião se expõe ao mundo quanto tendências internacionais nele se refletirão. Ao contrário do foco econômico de Debord (1992), podemos observar múltiplos fluxos. Appadurai (1994, p. 312-313) descreveu esses fluxos da cultura global com etnopanoramas, midiapanoramas, tecnopanoramas, finançopanoramas e ideopanoramas:

Valho-me desses termos, com um sufixo comum "panorama", para indicar, em primeiro lugar, que não se trata de relações objetivamente dadas que têm a mesma aparência a partir de cada ângulo de visão, mas, antes, são interpretações profundamente perspectivas, modeladas pelo posicionamento histórico, linguístico e político das diferentes espécies de agentes: os estados nacionais, as multinacionais, as comunidades diaspóricas, bem como os grupos e movimentos subnacionais (religiosos, políticos ou econômicos), e até mesmo os grupos intimamente mais relacionados, como vilas, os bairros e os grupos familiares. $\mathrm{Na}$ realidade, o agente individual é o último local deste conjunto de panoramas, pois os mesmos são eventualmente percorridos por agentes que ao mesmo tempo conhecem e constituem formações mais amplas, em parte pelo seu próprio sentido daquilo que essas paisagens oferecem.

Um megaevento esportivo permite um olhar para esses fluxos fluidos e irregulares como através de uma lente. Os diversos atores envolvidos, mesmo alguns deles marginalizados, participaram desses fluxos experimentando suas consequências. Vejamos alguns exemplos concretos do Pan-Americano de 2007.

Antes do Pan-Americano de 2007, os últimos megaeventos esportivos que haviam ocorrido no Brasil foram a Copa do Mundo de 1950 e os Jogos 
Pan-Americanos de 1963, em São Paulo. Eventos desse porte ficaram por quatro décadas distantes do Brasil. No final do século XX, o Brasil voltou a demonstrar interesse, passando a se candidatar a sede desses megaeventos esportivos, obtendo êxito nas edições do Pan-Americano de 2007, Copa do Mundo de 2014 e Jogos Olímpicos de 2016. Esse desenvolvimento está, no caso do Rio de Janeiro, estreitamente conectado ao ex-prefeito César Maia, eleito pela primeira vez em 1993 e reeleito em 2001 e 2005, terminando seu mandato em 2008. César Maia foi o prefeito responsável pela construção da autoestrada Linha Amarela e dos estádios² do Pan de 2007.

Cruz (2009) chama esses projetos de Grandes Projetos Urbanos (GPUs), que seriam, segundo Benedicto (2008/2009), a expressão de uma gestão urbana empresarial e neoliberal e, dessa forma, parte de um finançopanorama. A característica desse tipo de governo é que a administração da cidade favorece alguns poucos projetos grandes que são, do ponto de vista da iniciativa privada, economicamente rentáveis. Por isso, os projetos surgem tipicamente de parcerias público-privado (PPPs). A Linha Amarela é um típico exemplo: foi construída com dinheiro da prefeitura, mas está sendo administrada por uma empresa privada, a Lamsa (Linha Amarela S.A.). Vários estádios dos Jogos Pan-Americanos funcionam da mesma maneira. O estádio do remo na Lagoa - zona sul do Rio de Janeiro - foi renovado e ampliado parcialmente com dinheiro público e dinheiro da empresa privada Glen. Depois dos jogos, essa empresa transformou o estádio em um shopping center e recolhe, sozinha, os lucros do negócio (Behnken; Godoy, 2008/2009, p. 16).

Ou seja, nesses GPUs a prefeitura não investe em serviços públicos gratuitos e essenciais para seus cidadãos, como hospitais ou escolas, mas procura investimentos rentáveis, principalmente na área do lazer. Esses GPUs deveriam incentivar a iniciativa privada e, dessa forma, animar o desenvolvimento urbano. Muitas vezes, espera-se dos megaeventos esportivos exatamente esse efeito: um investimento pontual único em um evento que depois alavanca as melhorias urbanas com esforço mínimo das instituições públicas. Não há um planejamento em longo prazo, mas a busca dos efeitos rápidos com projetos chamativos. O arquiteto do Engenhão, Carlos Porto, chamou essa estratégia

2 Estádio João Havelange (Engenhão), Piscina Maria Lenk, Arena Multiuso e Velódromo.

Horizontes Antropológicos, Porto Alegre, ano 19, n. 40, p. 65-88, jul./dez. 2013 
de "acupuntura urbana", ou seja, a implantação pontual de GPUs, que deveriam influenciar todo seu entorno positivamente. ${ }^{3}$

Em 1996 e 2002, foram elaborados dois planos estratégicos pela prefeitura para a cidade do Rio de Janeiro, visando melhorias na área de turismo, eventos e cultura, ou seja, áreas percebidas como economicamente rentáveis. A coluna central dos planos foi a realização de Jogos Olímpicos no Rio de Janeiro, por isso, em 1996, a cidade apresentou oficialmente seu projeto de candidatura aos Jogos Olímpicos de 2004 ao Comitê Olímpico Internacional. Essa iniciativa não obteve êxito e o Rio foi eliminado da concorrência já na primeira fase, em 1998. Mais tarde Atenas foi confirmada como sede dos Jogos de 2004.

Nessa época, surge a ideia da construção de um estádio olímpico, inicialmente em Jacarepaguá e posteriormente em Engenho de Dentro. $\mathrm{O}$ arquiteto Carlos Porto se lembra:

Na prefeitura andei em várias áreas até finalmente aí em 95 eu fui convidado a ser diretor da empresa, uma empresa chamada RioUrbe. A RioUrbe era uma empresa de urbanização da prefeitura e eu fui convidado a ser diretor de projetos da RioUrbe. Nessa altura do campeonato o prefeito, não o secretário de Urbanismo, na verdade um secretário poderoso, era o Luiz Paulo Conde, que veio a ser prefeito da cidade e é um bom arquiteto. Eu conheci o Conde de uma premiação do IAB, do Instituto de Arquitetos [do Brasil] e ele era júri do concurso anual de premiação do Instituto de Arquitetos e premiou dois projetos que eu tinha colocado lá. E aí trocamos uma ideia, mas eu não tinha intimidade maior com o Conde, ele era apenas um bom arquiteto que conheci o trabalho e ele gostou do meu trabalho, etc. Quando ele virou secretário e sabia que eu era funcionário público ele me convidou ser diretor de projeto, portanto dessa empresa. [...] Começa a sugerir a cobertura completa sobre pelo menos a projeção da plateia para ter mais conforto, banheiros melhores, alguns outros adendos ao projeto, quer dizer coisas adicionadas ao projeto como museu, restaurante e assim excessivamente. Eu acho que a gente ainda estava muito atrás disso, quando então com a possibilidade de propor um estádio para as Olimpíadas, o Rio de Janeiro foi candidato para as Olimpíadas de 2004, a sediar as Olimpíadas de 2004. Volto à história de o Conde então ter me pedido um projeto público na época da RioUrbe para um estádio municipal.

3 Entrevista concedida a mim em 2009. Seguem várias citações desta entrevista. 
Chama a atenção o fato de não ter havido licitação pública, mas sim um funcionário da empresa da própria prefeitura ter sido diretamente chamado para fazer a proposta do estádio novo. Isto foi em $1995,{ }^{4}$ ou seja, quando se oficializou a candidatura; já em 1996, a discussão sobre arquitetura e localização do estádio havia acontecido no interior da prefeitura, sem uma discussão pública.

O projeto foi arquivado com a eliminação do Rio de Janeiro e reativado com a candidatura do Rio de Janeiro aos Jogos Pan-Americanos de 2007. Essa candidatura pareceu ser um passo estratégico do Comitê Olímpico Brasileiro e da prefeitura para conseguir futuramente os Jogos Olímpicos: ${ }^{5}$

Quando apareceu, quando Rio venceu a concorrência com São Paulo para sediar os Jogos Pan-Americanos. Isso é no final de 2002. A prefeitura se lembrou que tinha esse projeto já com nível de desenvolvimento bastante razoável. Então nos chamou. Eu já tinha saído da prefeitura, tinha me aposentado em 2001, quer dizer terminou meu período na prefeitura. Então nos chamou para estudar rapidamente esse projeto. Ver se cabia num terreno que aquele terreno lá de Engenho de Dentro, que era um terreno antigo da Estrada de Ferro e que de uma estação de manutenção da estrada de ferro, da ferrovia e que tava abandonado. O Comitê Olímpico tinha obtido uma concessão para fazer um centro de treinamento lá naquele troço. Então entre Comitê Olímpico e prefeitura se determinou que aquele fosse o terreno escolhido. Não é fácil você numa cidade dessa você achar um terreno que tenha $250.000 \mathrm{~m}^{2}$ com uma certa facilidade de transporte público, enfim. (Arquiteto Carlos Porto). ${ }^{6}$

4 Há muitas especulações sobre a semelhança entre os estádios Luz, em Lisboa, e o Engenhão. Carlos Porto comenta o assunto: "O Benfica derrubou e construiu um outro próximo. Esse novo estádio do Benfica, aquele que também tem uns arcos vermelhos. E que, aliás, é uma coisa curiosa porque o primeiro desenho do nosso estádio em arcos é de 95 , publicado em jornal e revista. E o do Benfica já é um estádio do HOK, do escritório HOK, mas é um estádio de projeto talvez publicado em 2000, 2000 e pouco, quer dizer. Então se pergunta: você baseou seu projeto no Benfica? Digo não, ele é capaz de ter olhado o nosso. Mas meu, pelo menos a publicação nossa é anterior. Publicação em jornal, em matéria, etc. e tal. Não, isso é besteira, isso é bobagem. Tô brincando porque isso não existe, porque hoje você tem influências de todos os lados, influência te pega, sem você perceber, uma lembrança, um gesto, ainda mais em arquitetura, em arte."

5 A candidatura ao Pan-Americano de 2007 foi apenas um desses passos estratégicos. Além disso, o Rio de Janeiro se candidatou para sediar os Jogos Sul-Americanos de 2002 e os Jogos Militares de 2011 (ambos com sucesso), a FIFA Copa do Mundo de Clubes de 2000, várias FIFA Copa do Mundo de Beach Soccer e a FIFA Copa do Mundo de Futsal de 2008 (todos com sucesso). Além disso, o Brasil era candidato para sediar a FIFA Copa do Mundo de Futebol de 2006 (sem sucesso).

6 A candidatura oficial se deu em 2001 e a escolha, em 2002. Não houve concorrência com São Paulo. Esta aconteceu na disputa pela candidatura aos Jogos Olímpicos de 2012.

Horizontes Antropológicos, Porto Alegre, ano 19, n. 40, p. 65-88, jul./dez. 2013 
Ou seja, o terreno das oficinas da Estrada de Ferro em Engenho de Dentro foi escolhido por ter sido considerado suficientemente grande, com uma situação de posse favorável e com bom acesso por trem e carro (Linha Amarela). Em 2002, o Rio foi confirmado como sede do Pan-Americano de 2007 pela Organización Deportiva Americana (ODEPA), e o Engenhão se tornaria a principal obra desse evento. A partir daí, o bairro de Engenho de Dentro se tornou o palco central de disputas e aspirações que envolvem um megaevento esportivo, sendo que a principal categoria perceptível nos discursos em torno dessa disputa é o legado. Legado entendido como melhorias para todos os cidadãos do bairro, da cidade e do país.

Para Horne e Manzenreiter (2006, p. 2) um megaevento esportivo possui sete características principais: 1) é um evento cultural, comercial e esportivo de escala grande; 2) tem um caráter dramático; 3) tem um apelo popular massificado; 4) tem significado internacional; 5) tem consequências significantes para a cidade ou país-sede; 6) provoca uma atenção imensa da mídia; e 7) representa uma descontinuidade no andamento ordinário de campeonatos esportivos.

Nesse momento, interessa principalmente o ponto 5 , as consequências significantes. A candidatura para sediar um megaevento esportivo é feita através das federações esportivas responsáveis. No caso dos Jogos PanAmericanos, o Comitê Olímpico Brasileiro $(\mathrm{COB})$ entregou a candidatura à ODEPA; no caso dos Jogos Olímpicos, o mesmo COB entregou ao Comitê Olímpico Internacional (COI) e, no caso de uma Copa do Mundo, a CBF entregou a candidatura à FIFA. E as federações internacionais COI e FIFA concedem o direito de sediar o evento às federações nacionais. Em outras palavras, o contrato é feito entre entidades privadas orientadas para o lucro, porém as federações nacionais dependem, para essas candidaturas, do apoio dos governos locais e nacionais, ou seja, de fluxos do ideopanorama.

Isso significa que em todas essas candidaturas o $\mathrm{COB}$ e a $\mathrm{CBF}$ tiveram garantias de apoio ao evento dos governos municipal, estadual e federal. Apoiar significa, em grande medida, financiar. Sendo assim, a prefeitura da cidade do Rio de Janeiro como instituição pública precisa investir seus recursos escassos em um evento privado. Esse amálgama de interesses públicos e privados leva a uma mistura pouco transparente entre instituições públicas e privadas, assim como ocorreu no Pan-Americano de 2007, gerando desconfianças. Em segui$\mathrm{da}$, os poderes governamentais precisam justificar tais investimentos como 
essenciais ao bem-estar da cidade. É o que ocorre com aquilo descrito como legado do evento. Os políticos representam a população toda e, portanto, são obrigados a (dizer) defender um legado para toda a população e não só para os membros do comitê organizador, que é uma entidade privada.

Esse legado normalmente é formulado pelos representantes políticos e esportivos de uma forma bastante genérica e não em exemplos específicos locais. Exemplificamos um brainstorming sobre possíveis legados positivos para os moradores da região do Engenho de Dentro. Novos empregos seriam bem-vindos a um bairro que perdera com o fim das oficinas, seu principal empregador. O secretário de Obras da prefeitura do Rio de Janeiro havia prometido em entrevista (Revista Obras do Pan, 2007, p. 23) que o Engenhão será “[...] uma arena onde funcionarão 50 lojas. Vai ter vida permanente." O arquiteto Carlos Porto confirmou a ideia de um shopping center com cinema integrado no Engenhão, que pelo menos no Pan-2007 não existia, mas poderia ser construído até os Jogos Olímpicos em 2016.

O próprio estádio poderia ser um espaço de lazer e esporte para a população residente. O Engenhão possui dois campos de futebol e pistas de atletismo, entretanto o estádio foi alugado ao clube Botafogo Futebol e Regatas e não é aberto aos moradores durante a semana. Outro legado poderia ser a valorização das casas e terrenos ao redor do estádio. Esse fator também representaria uma ameaça porque os moradores não sabem se as suas casas se tornariam alvo de especulação e, portanto, objetos de desapropriação. Finalmente constam na Revista Obras do Pan (2007, p. 20-21) várias obras de infraestrutura que foram feitas, como, por exemplo: renovação e ampliação da estação de trens, pavimentação de ruas, implantação de meio-fio, arborização, iluminação e sinalização pública.

Essas obras são necessárias porque um estádio é também um peso para uma comunidade, que terá de conviver com um aumento significativo de trânsito e barulho em cada evento esportivo que acontece no local. Enfim, a construção do Engenhão gera consequências ambíguas para o bairro, mostrando as irregularidades e flexibilidades nos fluxos, nesse caso do finançopanorama. É interessante observar que os moradores já parecem ter recebido a obra com orgulho, apesar de uma possível diminuição da qualidade de vida. Saí durante o Pan-Americano de 2007 do estádio e fui beber algo num bar próximo, onde falei com uma moradora que me disse: "Este estádio é a melhor coisa que o César [Maia, prefeito] fez. Já melhorou muito a nossa vida." No desenvolvimento da conversa percebi que a moradora nunca havia entrado no estádio e nem pretendia entrar. Cruz $(2009$, p. 11) observa também o aumento do 
sentimento de orgulho ao citar a fala de uma moradora: "Agora já posso dizer que moro no Engenho de Dentro. O estádio é uma referência."

Pensando em um nível municipal existem vários pacotes de propostas (ideopanorama) ligadas aos megaeventos esportivos, que constam nos planos estratégicos citados por Benedicto (2008/2009) e o Programa de Aceleração do Crescimento, que é uma iniciativa do governo federal. As propostas são muito parecidas. O Rio de Janeiro, como uma metrópole, apresenta problemas graves de desigualdade social, segurança pública, transporte público precário, poluição do meio ambiente, incluindo uma falta de itens básicos como educação, saúde e moradia. O Comitê Organizador do Pan-Americano de 2007 reagiu com uma candidatura que prometeu como legado, por exemplo, a construção de novas linhas de metrô, investimentos em projetos sociais e segurança pública, acesso da população aos estádios depois dos jogos, ganhos através da estimulação econômica e transformação social para todos. Essas propostas se inserem principalmente no tecnopanorama e se repetem na candidatura para os Jogos Olímpicos de 2016.

Durante a preparação para o Pan-Americano de 2007, se tornou rapidamente claro que não era possível cumprir essas promessas. A solução era a criação de algumas ilhas de excelência, ou seja, os estádios e ginásios, que poderiam ser mostrados na televisão para um público nacional e internacional. Os organizadores foram obrigados a se concentrar nessas áreas. O legado imediato dos habitantes foi transformado num legado de marketing, ou seja, um midiapanorama, que deveria se transformar mais tarde num legado social e econômico. Para conseguir essas transformações, a cidade precisa ganhar dinheiro atraindo investidores, necessitando, para isso, agir como competidor em um mercado internacional. A imagem que será transportada através da mídia de massa se torna o foco principal:

Os jogos Pan-Americanos serão o maior evento depois dos jogos de 1966 (Jogos Pan-Americanos de São Paulo) e vêm ao encontro da política de maior participação do Brasil no cenário mundial, como as operações de paz no Haiti, a vaga permanente no Conselho de Segurança da ONU, e a organização do país de uma olimpíada. (Ricardo Laser, representante do Governo Federal, na primeira Audiência Pública da Comissão Especial do Pan, em Maio de 2005). ${ }^{7}$

Citado em Cruz (2009, p.10), sendo que ele se refere ao Pan de 1963 e o nome correto do representante do governo é Ricardo Leyser.

Horizontes Antropológicos, Porto Alegre, ano 19, n. 40, p. 65-88, jul./dez. 2013 
A citação mostra que um megaevento esportivo não tem apenas consequências locais e municipais, mas também nacionais e internacionais. Em nível federal há esperanças que não só o Rio de Janeiro, mas o Brasil inteiro tenha benefícios com o Pan-Americano de 2007, a Copa do Mundo de 2014 e a Olimpíada de 2016, que iriam além de melhorias econômicas (finançopanorama). Esperam-se ganhos políticos e até uma vaga permanente no Conselho de Segurança da ONU, uma vaga de altíssimo prestígio e representada como quase impossível de se alcançar (ideopanorama). O uso do esporte como ferramenta política está se tornando comum. Na missão da paz da ONU, liderada pelo exército brasileiro no Haiti, foi organizado um Jogo da Paz entre as seleções do Haiti e do Brasil (etnopanorama). ${ }^{8}$

Megaeventos esportivos significam para políticos a oportunidade de aumentar sua influência, se projetar internacionalmente e garantir a sua base eleitoral. Além disso, é possível melhorar a imagem da própria cidade, do próprio país, tornando a região mais atrativa para investimentos e colaborações econômicas. Tais efeitos interessam a várias grandes empresas locais, que imaginam lucrar não só com as construções necessárias para o próprio evento, mas em longo prazo. A valorização do lugar é também desejada por imobiliárias. Os megaeventos esportivos se tornaram lócus importantíssimos de uma disputa internacional por recursos.

Ao que parece, países que pretendem se afirmar internacionalmente precisam sediar um megaevento esportivo. Dessa forma, é possível compreender a lista dos países-sedes de Copas do Mundo e Jogos Olímpicos como uma tradução das forças econômicas e políticas do momento (finançopanorama). Das sete Copas do Mundo de futebol e seis Jogos Olímpicos de verão que aconteceram entre 1980 e 2006, seis foram sediados na Europa (Espanha, Itália, França, Grécia e Alemanha), quatro na América do Norte (México e EUA), dois na Ásia (Coreia e Japão) e um na Austrália. Excetuando-se Grécia e México, essa lista representa as forças econômicas da época. Nenhum megaevento esportivo aconteceu na África ou na América do Sul. Esse panorama mudou claramente. Das cinco edições posteriores a esses eventos, dois

8 Este jogo é muito bem documentado no filme $O$ dia que o Brasil esteve aqui, que foi resenhado em Guedes e Curi (2013). 
ocorreram na América do Sul (Brasil), um na África (África do Sul), um na Ásia (China), um na Europa (Reino Unido) e nenhum na América do Norte.

Em 2001, o economista Jim O'Neill, do banco Goldman Sachs, formulou a tese de que os países Brasil, Rússia, Índia e China (Bric) se tornarão até 2050 as quatro principais forças econômicas do mundo (O’Neill, 2001). Dessa forma, não surpreende que esses países assumam uma posição de destaque entre as sedes de megaeventos esportivos no começo do século XXI.

Tabela 1. Megaeventos esportivos em países do Bric.

\begin{tabular}{ccc}
\hline Ano & Cidade/país & Evento \\
\hline 2008 & Pequim/China & Jogos Olímpicos de Verão \\
\hline 2011 & Nova Deli/Índia & Commonwealth Games \\
\hline 2014 & Sochi/Rússia & Jogos Olímpicos de Inverno \\
\hline 2014 & Brasil & Copa do Mundo de Futebol \\
\hline 2016 & Rio de Janeiro/Brasil & Jogos Olímpicos de Verão \\
\hline 2018 & Rússia & Copa do Mundo de Futebol \\
\hline
\end{tabular}

Nauright (2004, p. 1326) conclui que "developing economies such as Mexico, Brazil, South Korea, Malaysian India, South Africa and others have increasingly sought major events by which to promote their countries on a global stage". ${ }^{9}$ Ou seja, esses eventos são uma chance para os anfitriões melhorarem suas condições econômicas, a infraestrutura e se promoverem em um nível global. Porém, ao mesmo tempo representam um perigo, porque há típicas preocupações em relação a esses países, no que diz respeito à segurança pública, infraestrutura precária e cumprimento de cronogramas. Dimeo e Kay (2004) mostraram como a Copa do Mundo de Críquete de 1996, sediada em conjunto por Índia, Paquistão e Sri Lanka, causou dificuldades logísticas e políticas para os organizadores. Esses problemas foram muito destacados

9 Já há uma ampla literatura sobre megaeventos esportivos em países semiperiféricos: Dimeo e Kay (2004); Swart e Bob (2004); Black e Van Der Westhuizen (2004); Nauright (2004). 
pelos países de língua inglesa, reforçando estereótipos sobre a insuficiente capacidade de organização de países em desenvolvimento.

Mas os benefícios também não são garantidos em países desenvolvidos, como argumenta Atkinson et al. (2008, p. 420) analisando os Jogos Olímpicos de Londres de 2012:

Direct benefits are likely to be small, since impacts such as net additional tourism are likely to be limited. In addition, mega-event investments tend to displace better alternatives in the host city or beyond (for example, a substantial fraction of the facilities built for the Sydney 2000 Olympic Games has already been shut down). Indirect benefits, such as the host city's image and urban redevelopment, are more difficult to assess. Yet while a mega-event shines a spotlight on a city for a short period of time, most of the activities involve limited participation by local citizens and legacy effects are often quite small.

Há ainda posições mais críticas que chamam a atenção para o fato de que um megaevento pode representar até mesmo um inconveniente, sendo que, além disso, muitas vezes se esquece dos custos que envolvem sua realização:

[...] against any potential benefits of hosting sports events are likely to be a series of 'costs' that are rarely considered in ex ante or ex post economic assessments. These might include the effects of overcrowding and noise pollution, increased crime rates and 'hidden' costs associated with policing and security, 'removal of undesirables', sanitization and property cost inflation around venues. (Collins et al., 2007, p. 459).

Aliás, um grande estádio certamente é mais um inconveniente do que um ganho para a vizinhança direta, como é o caso dos moradores do Engenho de Dentro, por causa do barulho e do tumulto que o local atrai em cada jogo. Se a construção leva a uma valorização do solo, também produz a já mencionada inflação e expulsão dos moradores. Por causa dessas consequências indesejadas, provocadas pelos megaeventos esportivos, em muitas cidades-sedes se formam grupos de defesa dos direitos dos moradores (ideopanorama) que se sentem vítimas das especulações financeiras dos políticos, empresários e dirigentes esportivos (Raeder, 2008/2009, p. 11).

No caso do Pan-Americano de 2007, se formou o Comitê Social do Pan (CSP) em abril de 2005, por representantes de movimentos sociais e pesquisadores preocupados com a administração pública desse megaevento. Em 2009, 
o comitê mudou o nome para Comitê Popular Copa e Olimpíadas (CPCO), por causa das decisões sobre a Copa de 2014 e Olimpíada de 2016, entre outros. Esta organização formulou algumas exigências e apresentou preocupações sobre os eventos que iriam acontecer na cidade:

Orçamento transparente dos gastos públicos, amplamente divulgado e fiscalizado pela sociedade;

Participação da sociedade na decisão do planejamento e legado dos jogos; Investimentos em transporte público para todos;

Compromisso público de não haver remoções;

Destinação habitacional e popular da Vila Olímpica como em outras Olimpíadas; Destinação pública das arenas esportivas, não à privatização e instalações de "elefantes brancos";

Investimentos em programas sociais e esportivos;

Menos erros e mais acertos: que todos os investimentos sociais e de infraestrutura sejam cumpridos, mesmo sem as Olimpíadas. (Comitê Social do Pan, 2009).

O CSP acusa os comitês organizadores dos megaeventos de conceberem a cidade como mercadoria e não como espaço de moradia dos seus cidadãos. Tal pensamento justificaria um investimento maciço em áreas de interesse de lucro, remoção de populações de baixa renda dessas regiões, negligência dos interesses gerais da cidade. Além disso, o cronograma dos megaeventos criaria uma pressão, que provocaria a multiplicação dos gastos, o que abre a possibilidade para superfaturamentos. Raeder (2008/2009, p. 10-25) e Benedicto (2008/2009, p. 9-15) documentam essas preocupações, e também mencionam que de fato houve conflitos sociais graves na preparação do Pan-Americano de 2007, incluindo censura, remoções de favelas e incidentes violentos envolvendo a polícia.

A preocupação central para todos os envolvidos é: será que um megaevento justifica o investimento pesado de recursos públicos? Enquanto os políticos e dirigentes defendem, os movimentos sociais são contrários ao gasto. A verdade é que é impossível contabilizar gastos e ganhos e perceber os efeitos em longo prazo do marketing, da infraestrutura e de outros investimentos. Sem dúvida, esses eventos levantam o orgulho e a autoestima dos moradores, o que pode provocar efeitos positivos em outras áreas da vida. Também não é possível contabilizar definitivamente os investimentos que foram feitos em dinheiro, que aparenta ser algo objetivo e contável. O Pan-Americano de 2007 foi orçado em R 720 milhões e totalizou R \$ 3,4 bilhões em gastos de 
recursos públicos, o que significa cinco vezes o valor original (Cruz, 2009, p. 11). À primeira vista trata-se de um desperdício muito grande.

O economista alemão Preuss (2008) apresentou em 2008 uma pesquisa sobre os gastos e ganhos da Alemanha durante a Copa do Mundo de 2006. Fazendo referência apenas aos recursos que os diferentes níveis de governo investiram e os ganhos obtidos através de impostos adicionais, o economista conclui que aquela contabilidade quase se equilibra. Além disso, a conta não leva em consideração as consequências invisíveis como a atmosfera, o ganho de conhecimento, o orgulho e as consequências em longo prazo como uma nova infraestrutura, turismo, investimentos e melhora da imagem.

Tabela 2. Custos dos Jogos Olímpicos.

\begin{tabular}{ccc}
\hline Ano & Sede & Gasto em milhões US\$ \\
\hline 1996 & Atlanta & 2021 \\
\hline 2000 & Sydney & 4788 \\
\hline 2008 & Pequim & 36.000 \\
\hline 2016 & Rio de Janeiro & 14.400 (estimativa) \\
\hline
\end{tabular}

Fonte: Preuss (2008)

Se a intenção do Pan-Americano de 2007 foi mostrar que o Brasil é capaz de organizar megaeventos esportivos e se qualificar dessa forma para outros (tecnopanorama), então é possível considerar que o Pan-2007 foi um sucesso total. No final de 2007, a FIFA decidiu conceder ao Brasil o direito de organizar a Copa do Mundo de futebol de 2014 e, em outubro 2009, o COI escolheu o Rio de Janeiro como cidade-sede dos Jogos Olímpicos de 2016.

O principal estádio da Copa do Mundo será o Maracanã e das Olimpíadas, o Engenhão. As candidaturas obviamente tentam esconder as mazelas e destacar os pontos fortes do candidato. No caso do Rio de Janeiro, o argumento central enfatizava a vocação que a cidade teria para o esporte e, portanto, para as Olimpíadas:

Brazil offers PASO its quintessential city, where events reverberate internationally as in few other places in the world. The City of Rio de Janeiro, known as 
the "CIDADE MARAVILHOSA", has a naturally cheerful, friendly and peaceful citizenry, who have an unparalleled love of life. Cariocas are passionate for sports and practice them daily [...]. (Rio Pan-2007, 2002, p. 183).

Nauright (2004, p. 1328) argumenta que "global sports events can lead to the promotion of imagined, partial and fictional representational of local identities and histories". Esse efeito foi possibilitado com a relação criada entre os espaços públicos da praia, da Lagoa e do Parque da Tijuca e as atividades esportivas espontâneas e lúdicas dos cariocas. A estratégica de marketing evoca o título do trabalho de Araújo (1993), A vocação do prazer. Trata-se de um exemplo para o ideopanorama.

Esse tipo de marketing insinua também que os custos dos jogos não são altos, porque a própria cidade oferece naturalmente o lugar para as competições sem a necessidade de construções. Os altos custos são, portanto, uma preocupação dos organizadores e uma forma de diminuir os gastos e garantir o uso posterior dos estádios é a já citada PPP. O Engenhão é um exemplo disso. O estádio foi construído pelo poder público. Depois do Pan-Americano de 2007 houve uma concessão e o Engenhão foi alugado por R $\$ 36.000,00$ mensais ao clube Botafogo, que a partir daí se tornou responsável por sua manutenção (Botafogo vence..., 2007).

Interpretei no presente artigo megaeventos esportivos como "torneios de valor" globalizados, nos quais em um curto espaço de tempo e em um lugar específico, estão em jogo os diversos fluxos dos panoramas da globalização, como descreve Appadurai (1994, 2008). Este instrumental teórico mostra-se apto para analisar megaeventos esportivos, oferecendo a possibilidade de se ir além das simples dicotomias positivo/negativo ou bem $/ \mathrm{mal}$. Ao contrário disso, a análise aqui empreendida mostra que as consequências desses eventos, normalmente denominadas de "legado", são muito complexas, amplas e variáveis. Tanto que é praticamente impossível se fazer um balanço definitivo. Principalmente as análises econômicas, que tentam fazer a conta dos custos e lucros, parecem insuficientes, porque desconsideram o imenso valor simbólico.

Appadurai (2008) se inspirou na sua concepção de "torneio de valor" nos ritos indígenas denominados potlatch, nos quais aquele que gasta mais, tem o melhor status. Nesse sentido, seria mais profícuo considerarmos os megaeventos esportivos como potlatchs contemporâneos e globalizados e não como eventos economicamente racionais. 


\section{Referências}

APPADURAI, A. Disjunção e diferença na economia cultural global. In: FEATHERSTONE, M. Cultura global: nacionalismo, globalização e modernidade. Petrópolis: Vozes, 1994. p. 311-327.

APPADURAI, A. A vida social das coisas: as mercadorias sob perspectiva cultural. Niterói: EdUFF, 2008.

ARAÚJO, R. M. B. A vocação do prazer. Rio de Janeiro: Rocco, 1993.

ARCHETTI, E. Masculinidades: fútbol, tango y polo en la Argentina. Buenos Aires: Antropofagia, 2003.

ATKINSON, G. et al. Are we willing to pay enough to 'back the bid'?: valuing the intangible impacts of London's bid to host the 2012 Summer Olympic Games. Urban Studies, v. 45, n. 2, p. 419-444, 2008.

BEHNKEN, L. M.; GODOY, A. O relacionamento entre as esferas pública e privada nos Jogos Panamericanos de 2007. Esporte e Sociedade: Revista Digital, ano 4, n. 10, nov. 2008/fev. 2009. Disponível em: <http://www.uff.br/ esportesociedade/pdf/es1006.pdf>. Acesso em: 3 out. 2009.

BENEDICTO, D. Desafiando o coro dos contentes: vozes dissonantes no processo de implementação dos Jogos Pan-Americanos, Rio 2007. Esporte e Sociedade: Revista Digital, ano 4, n. 10, nov. 2008/fev. 2009. Disponível em: <http://www.uff.br/esportesociedade/pdf/es1007.pdf >. Acesso em: 3 out. 2009 .

BLACK, D. R.; VAN DER WESTHUIZEN, J. The allure of global games for 'semi-peripheral' polities and spaces: a research agenda. Third World Quarterly, v. 25, n. 7, p. 1195-1214, 2004.

BOAS, F.; NUNT, G. Ethnology of the Kwakiutl. Smithsonian Institution, Bureau of American Ethnology, 35th Annual Report. Washington, DC: Smithsonian Institution, Bureau of American Ethnology, 1921. 
BOTAFOGO VENCE a licitação do Engenhão. Terra, 3 ago. 2007. Disponível em: <http://esportes.terra.com.br/futebol/brasileiro2007/ interna/0,„OI1807766-I8817,00.html>. Acesso em: 26 jan. 2010.

COLLINS, A. et al. Assessing the environmental consequences of major sporting events: The 2003/04 FA Cup final. Urban Studies, v. 44, n. 3, p. $457-$ 476, 2007.

COMITE SOCIAL DO PAN. Que cidade queremos? Rio de Janeiro, 2009. Panfleto.

CRUZ, M. C. M. Grandes projetos: transformações e rupturas nos espaços urbanos: o caso do "Engenhão", no Engenho de Dentro - RJ. Dissertação (Mestrado em Geografia)-Instituto de Geociências, Universidade Federal Fluminense, Niterói, 2009.

CURI, M. Espaços da emoção: arquitetura futebolística, torcida e segurança pública. Tese (Doutorado em Antropologia)-Instituto de Ciências Humanas e Filosofia, Universidade Federal Fluminense, Niterói, 2012.

DAMATTA, R. Universo do futebol: esporte e sociedade brasileira. Rio de Janeiro: Pinakotheke, 1982.

DEBORD, G. A sociedade do espetáculo. Rio de Janeiro: Contraponto, 1992.

DIMEO, P.; KAY, J. Major sports events, image projection and the problems of 'semi-periphery': a case study of the 1996 South Asia Cricket World Cup. Third World Quarterly, v. 25, n. 7, p. 1263-1276, 2004.

GUEDES, S. L; CURI, M. The Peace Game about Brazil's military presence in Haiti. In: CURI, M. Football in Brazil. Oxford: Routledge, 2013. No prelo.

HORNE, J.; MANZENREITER, W. Sports mega-events: social scientific analyses of a global phenomenon. Oxford: Blackwell, 2006.

MALINOWSKI, B. Argonautos do Pacifico Ocidental. São Paulo: Abril, 1978. 
MAUSS, M. Ensaio sobre a dádiva. Lisboa: Edições 70, 1988.

NAURIGHT, J. Global games: culture, political economy and sport in the globalised world of the 21st century. Third World Quarterly, v. 25, n. 7, p. 1325-1336, 2004.

O’NEILL, J. BRICS. Goldman Sachs, 2001. Disponível em: <http://www2. goldmansachs.com/ideas/brics/book/99-dreaming.pdf $>$. Acesso em: 3 out. 2009 .

PREUSS, H. Impactos econômicos de megaeventos: Copa do Mundo de Futebol e Jogos Olímpicos. In: DACOSTA, L. et al. Legados de megaeventos esportivos. Brasília: Ministério do Esporte, 2008. p. 79-90.

RAEDER, S. Conflitos no ordenamento territorial em sedes de megaeventos esportivos. Esporte e Sociedade: Revista Digital, ano 4, n. 10, nov. 2008/fev. 2009. Disponível em: <http://www.uff.br/esportesociedade/pdf/es1005.pdf $>$. Acesso em: 3 out. 2009.

REVISTA OBRAS DO PAN. Rio de Janeiro: Prefeitura do Rio de Janeiro, 2007.

RIO PAN-2007. Candidate city. Rio de Janeiro: Sir Speedy, 2002.

SAHLINS, M. Cultura na prática. Rio de Janeiro: EdUFRJ, 2007.

SWART, K; BOB, U. The seductive discourse of development: the Cape Town 2004 Olympic bid. Third World Quarterly, v. 25, n. 7, p. 1311-1324, 2004.

TURNER, V. Floresta de símbolos: aspectos do ritual ndembu. Niterói: EdUFF, 2005. 